\title{
A Statistical Distribution for the Solvency Ratio of Indian Non-Life Insurers
}

\author{
R K Sinha \\ Insurance Regulatory \& Development Authority (IRDA) \\ Hyderabad \\ M M Nizamuddin \\ Insurance Regulatory \& Development Authority (IRDA) \\ Hyderabad
}

Ameer Hassan

Insurance Regulatory \& Development Authority (IRDA)

Hyderabad.

\begin{abstract}
The Indian Insurance Industry, which was privatized in the year 1999, has witnessed steep growth in terms of its business statistics, such as number of insurance companies, number of policies issued, aggregate premium underwritten etc. However, many of the insurers are still struggling to break even after a decade of their business operations. The insurance companies are different from other companies, which take longer time to stabilize. The progress of stabilization of the new companies can be measured in many ways. One way is to analyze the level of volatility in the various financial ratios, in addition to their average levels. It may be generally expected that an older company will have lower volatility in its financial ratios than the new ones. This is because of better understating of business and knowledge gained over years of business. This is one of the indicators for judging the stabilization status of the company.

The solvency ratio is one of the most important financial ratios for an insurer, which signals the overall health of the company. Accordingly, it is an important figure, which any stakeholder in the industry would like to watch closely. It is generally monitored either on a quarterly or an annual basis depending on the regulatory requirements of the specific country. Insurance companies which may be in a good financial position at a given point of time may fall short of the solvency margin requirement in the next period because of uncertainties and unforeseen factors. Although it is difficult to assess when such a situation for an insurance company could happens, it remains an important task to get best estimates possible with the available data and other factors.

The paper attempts to study and analyze the solvency ratio of the non-life insurance companies in India and model it through a statistical distribution. It examines the differentials in its trend and movement in the public and private insurance companies (as public sector companies are very old companies, as compared to the private ones), amongst the private insurers and across the time. It does not find significant difference in the public and private insurers, as the public sector companies too appears to struggle with high level of volatility in their solvency ratios despite their long years of business experience. It is found that the 3parameter Burr distribution explains our quarterly time-series dataset of solvency ratio appropriately. Given
\end{abstract}


the observations are independently and identically distributed and the Burr distribution explains the dataset appropriately, the paper reveals that the default cases are expected to be more than the actual cases, as observed so far.

In the last, the paper suggests further studies on this, which may be taken up. For example, it suggests that a multiple linear regression analysis could be carried out to explain the variation in the solvency ratios through few independent variables and identifies them, which are likely to impact the solvency ratio of non-life insurance companies.

Keywords: Burr distribution, coefficient of variation, solvency ratio, available solvency margin, required solvency margin.

\section{Introduction}

The Indian Insurance Industry was privatized in the year 1999. Prior to privatization, there were only one life insurer and four non-life insurers, all of them in public sector, doing insurance business in India. The insurance industry underwent significant changes since privatization, with steep growth in terms of its business statistics, such as number of insurance companies, number of policies issued, aggregate premium underwritten etc. Although, this phenomenon is more prevalent in case of life insurance (business volume wise), the number of insurance companies in both life and non-life insurance segments continue to surge in tandem and both are around two dozen as of now. However, many of the insurers are still struggling to break even after a decade of their business operations. The insurance companies are different from other companies, which take longer time to break even and stabilize because of the nature of insurance business. The insurance business is not just buying and selling of products but rather it is a promise to pay to the insured in the occurrence of a contingent even in lieu of an amount, called premium. Accordingly, the actual cost of the product is known to the insurance company on a later date, may be several years, after the sale of a particular policy.
The progress of stabilization of the new companies can be measured in many ways. One way is to analyze the level of volatility in the various financial ratios, in addition to their average levels (central tendencies). One could generally expect that an older company will have lower volatility in its financial ratios than the new ones, although may not be always, as there could sudden events which may drag up/ down the financial ratios in a very period of span. These sudden and untoward events could be catastrophes, financial crisis, scams etc. Still, as the company ages, it will have better understating of business and knowledge, which should reflect in a less volatile figures of the financial statements.

Generally, the financial ratios of a company can be categorized into three groups, viz. the profitability ratios, efficiency ratios and liquidity ratios. The financial statements of insurance companies are rather complicated as compared to that of other companies, as its accounting techniques are largely based upon many actuarial and statistical assumptions and valuations, which include (actuarial) judgments. Insurance companies which may be in a good financial position at a given point of time may fall short of the solvency margin requirement in the next period because of uncertainties an unforeseen factors. Although it is difficult to assess when such a 
situation for an insurance company could happen, it remains an important task to get best estimates possible apart from other related information. Accordingly, the insurance companies are required to furnish solvency position to their regulators on a periodic basis which has a period, as prescribed by the regulators. Generally, the period is either annually or quarterly.

The Insurance Regulatory and Development Authority (IRDA), the regulatory body of India for the insurance sector, has prescribed guidelines vide IRDA (Assets, Liabilities and Solvency Margin of Insurers) Regulations, 2000. Both in case of life and non-life insurance segments, the insurers are required to furnish requisite information. The periodicity of furnishing it, which was annual till March 2008, has been made to quarterly with effect from June 2008 vide Circular No. 056/IRDA/ACTL/Solvency Margin/ February-07. This results in availability of two datasets on solvency ratios, viz. annually (for longer period) and quarterly (for shorter period). We have largely used the quarterly dataset for this study and restricted our study to non-life insurance only. The non-life insurance companies are required to furnish requisite details to IRDA through Form KG. The solvency ratio is the ratio of two numbers, viz. the Available Solvency Margin (ASM) and the Required Solvency Margin (RSM). The ASM is the excess of value of assets (furnished in Form IRDA - Assets-AA) over the value of liabilities (furnished in Form HG), with further adjustments as shown in Table III of Form KG. The format of the information required is provided as below (Table 1).

Table 1: Format for furnishing ASM and Solvency Ratio

\begin{tabular}{|c|c|c|c|}
\hline $\begin{array}{l}\text { Item No. } \\
\text { (1) }\end{array}$ & $\begin{array}{l}\text { Description } \\
\text { (2) }\end{array}$ & $\begin{array}{l}\text { Notes No. } \\
\text { (3) }\end{array}$ & $\begin{array}{l}\text { Amount } \\
\text { (4) }\end{array}$ \\
\hline 01 & $\begin{array}{l}\text { Available Assets in policyholders' Funds : } \\
\text { Deduct: }\end{array}$ & & \\
\hline 02 & Liabilities & & \\
\hline 03 & Other Liabilities & & \\
\hline 04 & Excess in Policyholders' funds $(01-02-03)$ & & \\
\hline 05 & $\begin{array}{l}\text { Available Assets in policyholders' Funds: } \\
\text { Deduct: }\end{array}$ & & \\
\hline 06 & Other Liabilities & & \\
\hline 07 & Excess in Policyholders' funds (05-06) & & \\
\hline 08 & Total ASM (04)+(07) & & \\
\hline 09 & Total RSM & & \\
\hline 10 & Solvency Ratios (Total ASM/Total RSM & & \\
\hline
\end{tabular}


As indicated above, the Solvency Ratio is the ratio of the amount of Available Solvency Margin to the amount of Required Solvency Margin. The Required Solvency Margin is determined by the Gross Premium, Net Premium, Gross Claims, Net Claims and associated factors. The format of furnishing this information is provided in Table 2.

Table 2: Format for furnishing RSM

\begin{tabular}{|c|c|c|c|c|c|c|c|c|}
\hline $\begin{array}{l}\text { Item } \\
\text { No. }\end{array}$ & $\begin{array}{l}\text { Description } \\
\text { (Class of } \\
\text { business }\end{array}$ & $\begin{array}{c}\text { Gross } \\
\text { Premium }\end{array}$ & $\begin{array}{c}\text { Net } \\
\text { Premium }\end{array}$ & $\begin{array}{c}\text { Gross } \\
\text { Incurred } \\
\text { claims }\end{array}$ & $\begin{array}{c}\text { Net } \\
\text { Incurred } \\
\text { claims }\end{array}$ & RSM-1 & RSM-2 & RSM \\
\hline (1) & (2) & (3) & (4) & (5) & (6) & (7) & (9) & (10) \\
\hline 01 & Fire & & & & & & & \\
\hline 02 & Marine (Cargo) & & & & & & & \\
\hline 03 & Marine (Hull) & & & & & & & \\
\hline 04 & Motor & & & & & & & \\
\hline 05 & Engineering & & & & & & & \\
\hline 06 & Aviation & & & & & & & \\
\hline 07 & Liability & & & & & & & \\
\hline 08 & Rural Insurance & & & & & & & \\
\hline 09 & Others & & & & & & & \\
\hline 10 & Health Insurance & & & & & & & \\
\hline 11 & TOTAL & & & & & & & \\
\hline
\end{tabular}

The RSM-1 in the above table is the Required Solvency Margin, which is based on the Premiums (Gross Premium and Net Premium). It is determined as twenty per cent of the amount which is the higher of the Gross Premium multiplied by a Factor $A$ as specified below and the Net Premium. Similarly, the RSM-2 in the above table is the Required Solvency Margin, which is based on the Incurred Claims (Gross Incurred Claims and Net Incurred Claims). It is determined as thirty per cent of the amount which is the higher of the Gross Incurred Claims multiplied by a Factor B as specified below and the Net Incurred Claims. Thus, mathematically they are:

RSM-1 $=0.20 *$ Maximum (Gross Premium * Factor A, Net Premium)

Similarly,

RSM-2 $=0.30 *$ Maximum (Gross Incurred Claims * Factor B, Net Incurred Claims)

The Factors $A$ and $B$, according to lines of business, are provide in Table 3. 
Table 3: Specified values of Factors A and B by Line of Business

\begin{tabular}{|c|l|c|c|}
\hline Item No. & Description (Class of business) & Factor A & Factor B \\
\hline$(1)$ & \multicolumn{1}{|c|}{$(2)$} & $(3)$ & $(4)$ \\
\hline 01 & Fire & 0.50 & 0.50 \\
\hline 02 & Marine: Marine Cargo & 0.70 & 0.70 \\
\hline 03 & Marine Hull: & 0.50 & 0.50 \\
\hline 04 & Motor & 0.85 & 0.85 \\
\hline 05 & Engineering & 0.50 & 0.50 \\
\hline 06 & Aviation & 0.90 & 0.90 \\
\hline 07 & Liability & 0.85 & 0.85 \\
\hline 08 & Rural Insurance & 0.50 & 0.50 \\
\hline 09 & Others & 0.70 & 0.70 \\
\hline 10 & Health Insurance: & 0.85 & 0.85 \\
\hline
\end{tabular}

IRDA has stipulated that every insurer should maintain a minimum of 1.50 , as the Solvency Ratio at all points of time. Regulatory intervention takes place if the same breaches 1.50 level. The companies need to put in fresh capital resulting in increase in ASM, and thus Solvency Ratio. The following section provides the time series data on the solvency ratio.

\section{Data and Methodology}

As mentioned in the introductory section, this study is limited to the non-life insurers. We have considered 12 insurers (four public and eight private) for the annual dataset. For the quarterly dataset, we have taken 16 insurance companies (four public and twelve private). This is in accordance with the availability of this information. While the annual data is available for six years viz. 2005-06 to 2010-11, whereas the quarterly data is available for 13 quarters viz. March 2008 to March 2011. This way, the data points are 72 and 208 for the annual and quarterly series respectively. Table 4 shows the solvency ratio of companies for the annual series. The first four companies are the public sector companies. 
Table 4: Solvency Ratio of Non-life Insurers (Annual - As on 31 $1^{\text {st }}$ March)

\begin{tabular}{|l|l|l|l|l|l|l|l|l|l|}
\hline Insurer & 2006 & 2007 & 2008 & 2009 & 2010 & 2011 & MEAN & SD & CV \\
\hline National & 1.08 & 1.76 & 2.22 & 1.56 & 1.60 & 1.34 & $\mathbf{1 . 5 9}$ & $\mathbf{0 . 3 9}$ & $\mathbf{0 . 2 4}$ \\
\hline New India & 3.09 & 3.57 & 4.00 & 3.41 & 3.55 & 2.90 & $\mathbf{3 . 4 2}$ & $\mathbf{0 . 3 9}$ & $\mathbf{0 . 1 1}$ \\
\hline Oriental & 1.97 & 2.17 & 1.91 & 3.41 & 1.56 & 1.34 & $\mathbf{2 . 0 6}$ & $\mathbf{0 . 7 3}$ & $\mathbf{0 . 3 5}$ \\
\hline United India & 2.23 & 3.00 & 3.24 & 3.32 & 3.41 & 2.89 & $\mathbf{3 . 0 2}$ & $\mathbf{0 . 4 3}$ & $\mathbf{0 . 1 4}$ \\
\hline Bajaj Allianz & .22 & 1.56 & 1.55 & 1.62 & 1.54 & 1.73 & $\mathbf{1 . 5 4}$ & $\mathbf{0 . 1 7}$ & $\mathbf{0 . 1 1}$ \\
\hline Cholamandalam & 2.51 & 2.63 & 2.00 & 1.02 & 1.76 & 1.61 & $\mathbf{1 . 9 2}$ & $\mathbf{0 . 6 0}$ & $\mathbf{0 . 3 1}$ \\
\hline HDFC ERGO & 1.78 & 1.69 & 2.02 & 2.48 & 1.49 & 1.71 & $\mathbf{1 . 8 6}$ & $\mathbf{0 . 3 5}$ & $\mathbf{0 . 1 9}$ \\
\hline ICICI Lombard & 1.29 & 2.08 & 2.03 & 2.03 & 2.07 & 1.56 & $\mathbf{1 . 8 4}$ & $\mathbf{0 . 3 4}$ & $\mathbf{0 . 1 8}$ \\
\hline IFFCO-TOKIO & 1.95 & 1.70 & 1.51 & 1.77 & 1.76 & 1.23 & $\mathbf{1 . 6 5}$ & $\mathbf{0 . 2 5}$ & $\mathbf{0 . 1 5}$ \\
\hline Reliance & 3.04 & 1.95 & 1.64 & 1.59 & 1.70 & 1.15 & $\mathbf{1 . 8 5}$ & $\mathbf{0 . 6 4}$ & $\mathbf{0 . 3 5}$ \\
\hline Royal Sundaram & 1.66 & 1.64 & 1.59 & 1.64 & 1.39 & 1.56 & $\mathbf{1 . 5 8}$ & $\mathbf{0 . 1 0}$ & $\mathbf{0 . 0 6}$ \\
\hline Tata AIG & 1.68 & 1.85 & 1.91 & 1.97 & 1.88 & 1.68 & $\mathbf{1 . 8 3}$ & $\mathbf{0 . 1 2}$ & $\mathbf{0 . 0 7}$ \\
\hline MEAN & 1.96 & 2.13 & 2.14 & 2.15 & 1.98 & 1.73 & & & \\
\hline SD & 0.66 & 0.62 & 0.75 & 0.82 & 0.73 & 0.58 & & & \\
\hline CV & $\mathbf{0 . 3 4}$ & $\mathbf{0 . 2 9}$ & $\mathbf{0 . 3 5}$ & $\mathbf{0 . 3 8}$ & $\mathbf{0 . 3 7}$ & $\mathbf{0 . 3 4}$ & & & \\
\hline
\end{tabular}

Source: Handbook on Indian Insurance Statistics 2010-11

From the table, it can be seen that the solvency ratios of public sector companies have also been quite volatile. This is somewhat in disagreement to the general understanding that the public sector companies, which have many years of business experience, should witness lower volatility. However, it may be assumed that subsequent to the privatization in year 2000, these companies are still in the process of re-aligning their business in the presence of acute price competitiveness. Although the length of this timeseries data is only 5 years, it can be seen from Figure 1 that there has been a consistent in the mean, standard deviation and co-efficient of variation, in the industry, during the last couple of years, which encourages us to go into a detailed inspection, as its quarterly figures are also available. The same is studied in the subsequent paragraphs. It may be noted that the computed means are the simple arithmetic (unweighted) means representing either the company-wise (over all years) values or the yearwise (over all companies, that is, industry total) values. Another approach could be to take weighted averages, giving different weights to the companies, possibly in proportion to their business volumes. However, this approach has not been used here because of other potential limitations and consequences. 


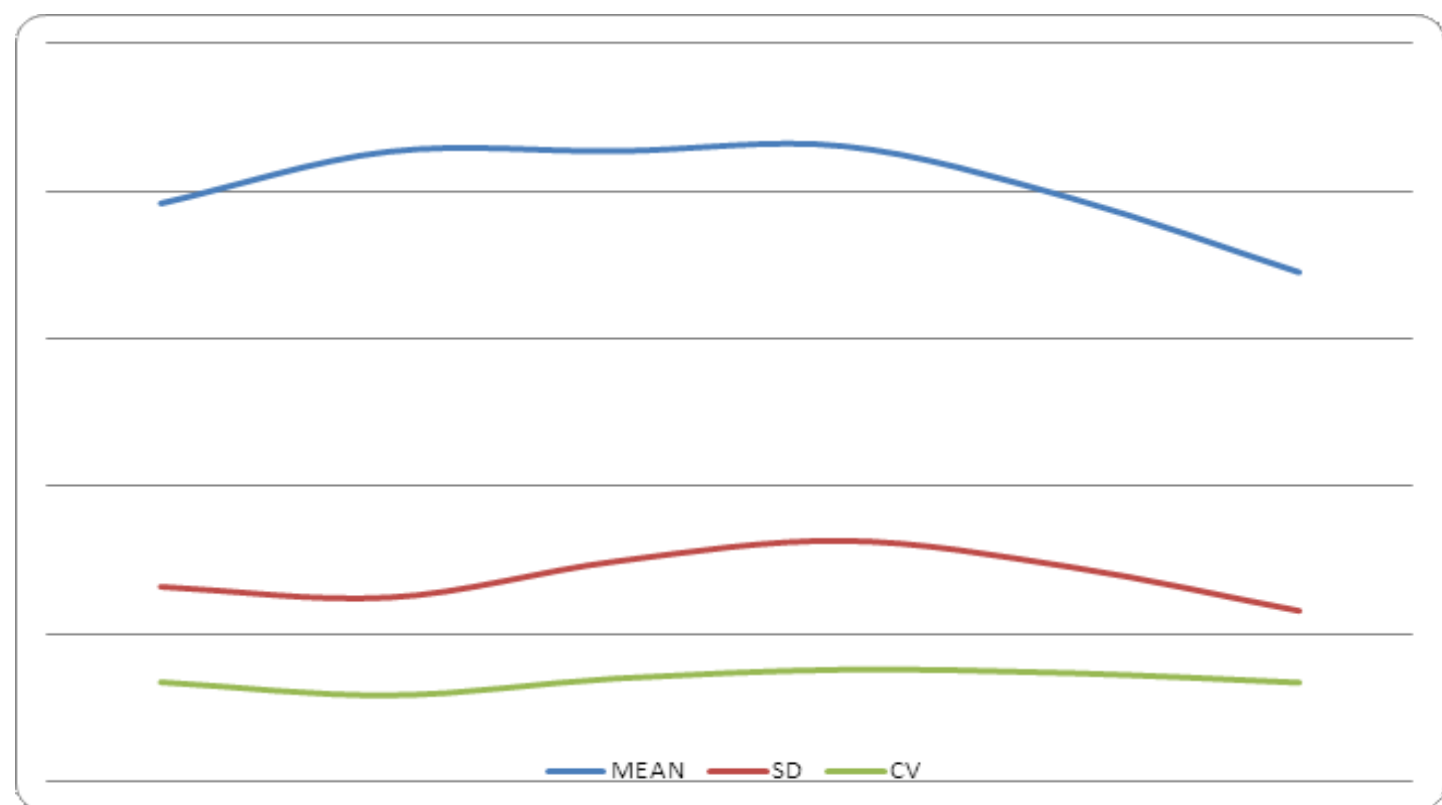

Figure 1: Solvency Ratio across the years (Annual)

The quarterly data of solvency ratio is given in Table 4. From the table, it is interesting to see that there is a consistent declination in mean, standard deviation and coefficient of variation at the industry level over the quarters.

Table 4: Solvency Ratio of Non-life Insurers (Quarterly)

Continued ....

\begin{tabular}{|l|c|c|c|c|c|c|c|c|}
\hline \multicolumn{1}{|c|}{ Insurer } & Mar 2008 & June 2008 & Sept 2008 & Dec 2008 & Mar 2009 & June 2009 & Sept 2009 & Dec 2009 \\
\hline National & 2.22 & $2.11^{*}$ & 2.00 & 1.67 & 1.56 & 1.60 & 1.75 & 1.63 \\
\hline New India & 4.00 & $3.89^{*}$ & 3.79 & 3.15 & 3.41 & 3.34 & 3.45 & 2.83 \\
\hline Oriental & 1.91 & 2.01 & 2.11 & 1.75 & 1.66 & 1.67 & 1.56 & 1.51 \\
\hline United India & 3.24 & 3.50 & 3.53 & 3.61 & 3.32 & 2.55 & 3.79 & 3.91 \\
\hline Bajaj Allianz & 1.55 & 2.48 & 2.30 & 1.85 & 1.62 & 2.18 & 2.18 & 2.18 \\
\hline Bharti AXA & $2.23^{\#}$ & 2.23 & 2.01 & 2.91 & 2.11 & 1.78 & 1.78 & 1.71 \\
\hline Cholamandalam & 2.00 & 1.87 & 1.72 & 1.60 & 1.02 & 2.14 & 1.65 & 1.56 \\
\hline Future Generali & 2.61 & 2.44 & 2.13 & 1.76 & 1.83 & 1.80 & 1.85 & 1.83 \\
\hline HDFC Ergo & 2.02 & 1.62 & 2.32 & 2.19 & 2.48 & 1.52 & 2.72 & 1.91 \\
\hline ICICI Lombard & 2.03 & 1.54 & 2.49 & 2.24 & 2.03 & 1.98 & 2.08 & 2.08 \\
\hline IFFCO Tokio & 1.51 & 1.98 & 1.91 & 2.30 & 1.77 & 2.37 & 2.33 & 2.22 \\
\hline Royal Sundaram & 1.59 & 1.89 & 1.59 & 1.51 & 1.64 & 2.51 & 2.10 & 2.07 \\
\hline Reliance & 1.64 & 3.77 & 2.96 & 1.88 & 1.59 & 2.60 & 2.37 & 1.91 \\
\hline
\end{tabular}




\begin{tabular}{|l|c|c|c|c|c|c|c|c|}
\hline Shriram & $1.97^{\#}$ & 1.97 & 1.97 & 1.98 & 1.94 & 1.99 & 2.06 & 2.18 \\
\hline TATA AIG & 1.91 & 1.76 & 1.65 & 1.88 & 1.97 & 1.92 & 1.85 & 1.83 \\
\hline Universal Sompo & 4.68 & 4.63 & 4.60 & 4.49 & 4.23 & 4.09 & 3.86 & 3.57 \\
\hline MEAN2.32 & 2.48 & 2.44 & 2.30 & 2.14 & 2.25 & 2.34 & 2.18 & \\
\hline SD 0.91 & 0.93 & 0.85 & 0.83 & 0.83 & 0.68 & 0.74 & 0.69 & \\
\hline CV $\mathbf{0 . 3 9}$ & $\mathbf{0 . 3 8}$ & $\mathbf{0 . 3 5}$ & $\mathbf{0 . 3 6}$ & $\mathbf{0 . 3 9}$ & $\mathbf{0 . 3 0}$ & $\mathbf{0 . 3 2}$ & $\mathbf{0 . 3 2}$ & \\
\hline
\end{tabular}

Continued ...

\begin{tabular}{|l|c|c|c|c|c|c|c|c|}
\hline Insurer & Mar 2010 & June 2010 & Sept 2010 & Dec 2010 & Mar 2011 & MEAN & SD & CV \\
\hline National & 1.60 & 1.61 & 1.52 & 1.53 & $\mathbf{1 . 3 4}$ & $\mathbf{1 . 7 0}$ & $\mathbf{0 . 2 5}$ & $\mathbf{0 . 1 5}$ \\
\hline New India & 3.55 & 3.50 & 3.22 & 3.22 & 2.90 & $\mathbf{3 . 4 0}$ & $\mathbf{0 . 3 5}$ & $\mathbf{0 . 1 0}$ \\
\hline Oriental & 1.56 & 1.54 & $\mathbf{1 . 2 6}$ & $\mathbf{1 . 4 1}$ & $\mathbf{1 . 3 4}$ & $\mathbf{1 . 6 4}$ & $\mathbf{0 . 2 5}$ & $\mathbf{0 . 1 5}$ \\
\hline United India & 3.41 & 3.46 & 3.77 & 3.46 & 2.89 & $\mathbf{3 . 4 2}$ & $\mathbf{0 . 3 7}$ & $\mathbf{0 . 1 1}$ \\
\hline Bajaj Allianz & 1.54 & 1.92 & 1.96 & 2.02 & 1.73 & $\mathbf{1 . 9 6}$ & $\mathbf{0 . 3 0}$ & $\mathbf{0 . 1 5}$ \\
\hline Bharti AXA & 2.38 & 2.43 & 1.62 & 1.69 & 1.70 & $\mathbf{2 . 0 4}$ & $\mathbf{0 . 3 8}$ & $\mathbf{0 . 1 9}$ \\
\hline Cholamandalam & 1.76 & 1.78 & 1.75 & 1.64 & 1.61 & $\mathbf{1 . 7 0}$ & $\mathbf{0 . 2 6}$ & $\mathbf{0 . 1 5}$ \\
\hline Future Generali & 1.54 & 1.68 & 2.05 & 2.12 & 2.06 & $\mathbf{1 . 9 8}$ & $\mathbf{0 . 3 0}$ & $\mathbf{0 . 1 5}$ \\
\hline HDFC Ergo & $\mathbf{1 . 4 9}$ & 1.75 & 1.71 & 1.95 & 1.71 & $\mathbf{1 . 9 5}$ & $\mathbf{0 . 3 8}$ & $\mathbf{0 . 1 9}$ \\
\hline ICICI Lombard & 2.07 & 1.78 & 1.66 & 1.63 & 1.56 & $\mathbf{1 . 9 4}$ & $\mathbf{0 . 2 8}$ & $\mathbf{0 . 1 5}$ \\
\hline IFFCO Tokio & 1.76 & 1.63 & 1.61 & 1.53 & $\mathbf{1 . 2 3}$ & $\mathbf{1 . 8 6}$ & $\mathbf{0 . 3 6}$ & $\mathbf{0 . 2 0}$ \\
\hline Royal Sundaram & $\mathbf{1 . 3 9}$ & 1.51 & 1.53 & 1.51 & 1.56 & $\mathbf{1 . 7 2}$ & $\mathbf{0 . 3 2}$ & $\mathbf{0 . 1 9}$ \\
\hline Reliance & 1.70 & 1.68 & 2.18 & 1.95 & $\mathbf{1 . 1 5}$ & $\mathbf{2 . 1 1}$ & $\mathbf{0 . 6 9}$ & $\mathbf{0 . 3 3}$ \\
\hline Shriram & 1.75 & 2.16 & 1.86 & 1.71 & $\mathbf{1 . 3 2}$ & $\mathbf{1 . 9 1}$ & $\mathbf{0 . 2 2}$ & $\mathbf{0 . 1 2}$ \\
\hline TATA AIG & 1.88 & 1.77 & 2.00 & 1.82 & 1.68 & $\mathbf{1 . 8 4}$ & $\mathbf{0 . 1 0}$ & $\mathbf{0 . 0 6}$ \\
\hline Universal Sompo & 3.15 & 2.72 & 2.58 & 2.49 & 2.14 & $\mathbf{3 . 6 3}$ & $\mathbf{0 . 9 2}$ & $\mathbf{0 . 2 5}$ \\
\hline MEAN2.03 & 2.06 & 2.02 & 1.98 & 1.75 & & & & \\
\hline SD 0.71 & 0.64 & 0.66 & 0.60 & 0.52 & & & & \\
\hline CV 0.35 & $\mathbf{0 . 3 1}$ & $\mathbf{0 . 3 3}$ & $\mathbf{0 . 3 0}$ & $\mathbf{0 . 3 0}$ & & & & \\
\hline
\end{tabular}

Source: Handbook on Indian Insurance Statistics 2010-11 
Note: ${ }^{*}$ and \# are the estimated values using their neighboring values, as they are not available. Values Underlined are default cases (solvency ratio $<1.50$ ).

Amongst the four public sector insurers, two insurers (viz. New India and United India) have maintained consistently higher solvency ratio (over 3.00), than the rest two insurers (viz. National and Oriental), which have hovered largely in the band of 1.50-1.75. The Oriental has defaulted 3 times in a row, out of a total of 10 defaults in 208 data points.

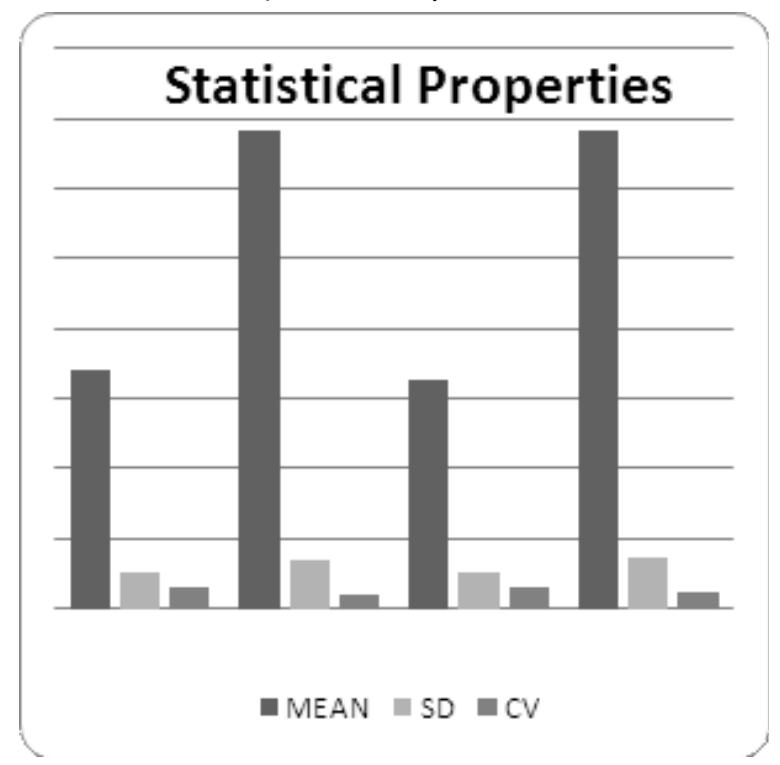

Figure 2: Solvency Ratio (Quarterly) - Public Insurers

In case of 12 private insurers, 6 companies have co-efficient of variation in the solvency ratio of more than 0.15 , while 6 companies have the same within 0.15 . Overall there is a trend of reduction in the mean, standard deviation and coefficient of variation over the years for private sector too, which is a step towards stabilization of companies, although the time-series data is too short, which limits the confidence level of the interpretation to some extent. Nevertheless, it serves as a good preliminary investigation into it. Figure 2 exhibits the trend of solvency ratio over years for the private insurers. From figure, it is observed that the Universal Sompo has a higher solvency ratio, although it is declining over time.

The private insurers have together defaulted in six occasions out of the total 10 defaults in the Industry during the period of current study. As indicated earlier, the defaults relates to the scenario of solvency ratio falling below 1.50 . This scenario leads to regulatory interventions, and companies are required to put more capital in order to increase the Available Solvency Margin (ASM) beyond 150 per cent of the Required Solvency Margin (RSM). This way the solvency ratio bounces back towards the positive territory ( $\left.e^{\prime \prime} 1.50\right)$. At the same time, it may not be a desirable event to maintain solvency ratio at a very high level from 1.50, because this might have side effects on other opportunities, such as, investment, competitiveness etc. Accordingly, a stabilized company is expect to maintain its solvency ratio in a narrower band over 1.50 with some cushion and low volatility in the variability in the solvency ratio, in terms of standard deviation and coefficient of variation. 


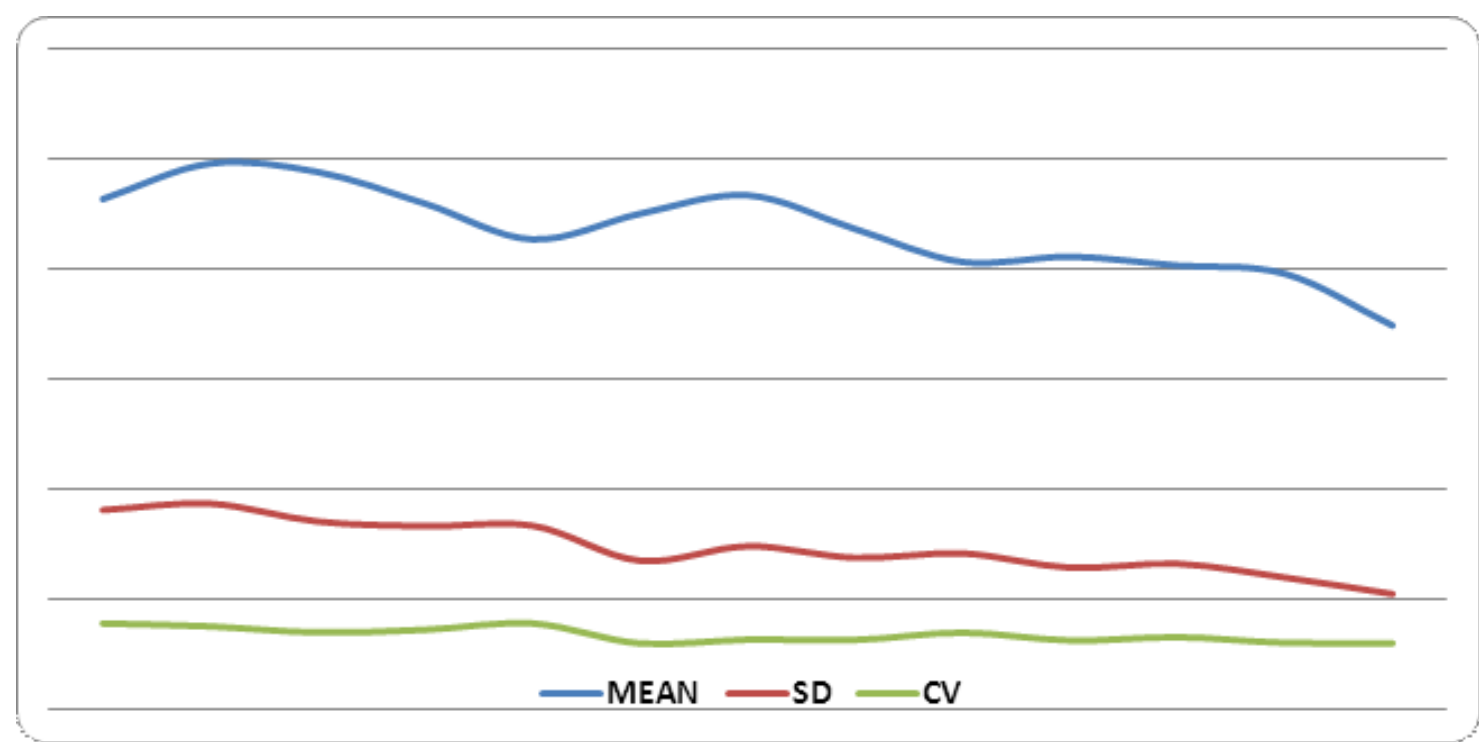

Figure 3: Statistical Properties of Solvency Ratio over Quarters

Figure 3 exhibits the mean, standard deviation and coefficient of variation of the Industry over quarters. From the figure, it can be seen that the industry has witnessed a slight (but gradual) decline in the solvency ratio over the 3 year time, viz. 20082011. Based upon the 208 data points, we now attempt to find a statistical distribution, which may explain the underlying dataset appropriately. Figure 4 exhibits the plot of solvency ratio in increasing order. The plot reveals that the slope of the linearity in the solvency ratio changes at around 1.50 and at around 2.20. Further, beyond 2.20 level, the solvency ratio goes up exponentially with the number of observations.

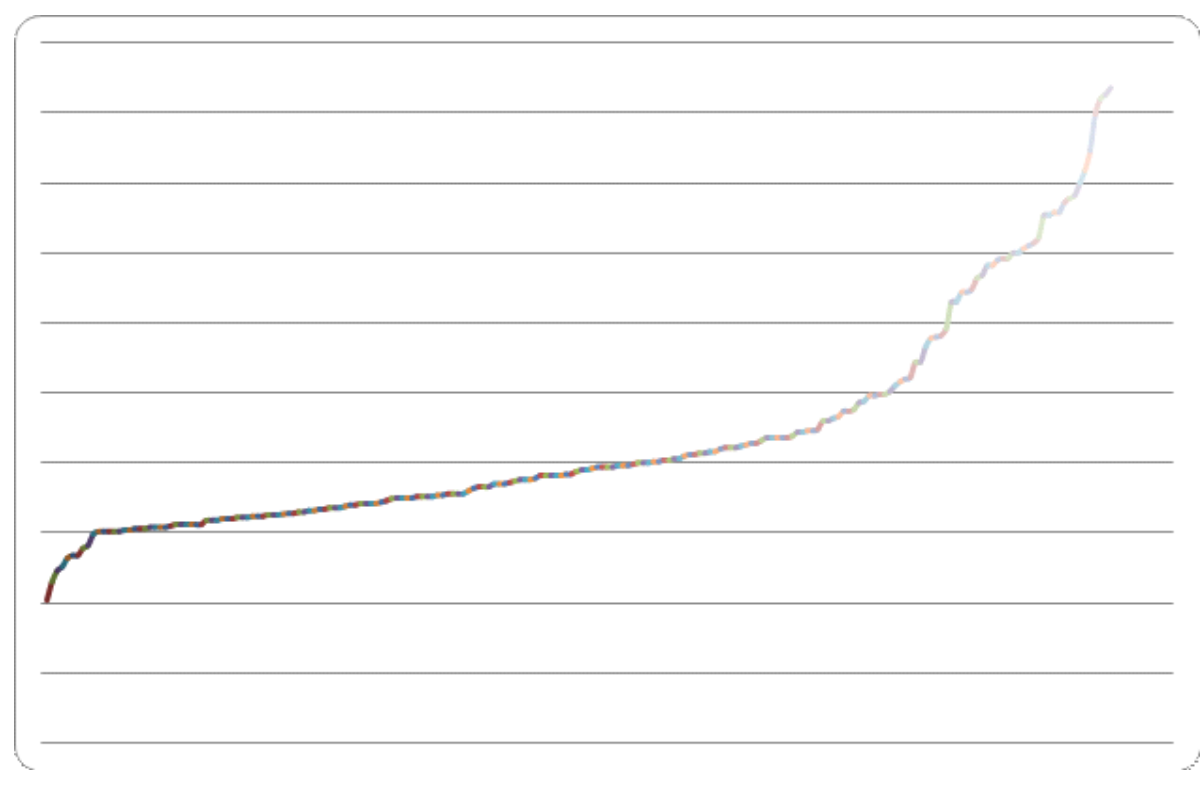

Figure 4: Plot of Solvency Ratio in Increasing Order 
For fitting of any dataset through a statistical distribution, it is assumed that the observations are independently and identically distributed (IID), however, it practice, it is too difficult to find such a data set. However, the level of closeness of observations towards IID assumption dictates the confidence level in the analysis. In our context, we take note of the fact that there are differences in the statistical properties of solvency ratios in the public and private sector insurers, amongst the private insurers themselves, and also across the years. However, these differences do not seem to be large enough to impact the violation of the IID assumption in a big way. Accordingly, we model the solvency ratio of all the data together. We observe that there have not been studies on modeling on the solvency ratio directly, although there are a few studies for modeling the loss ratio (incurred claims ratio), which influences the solvency ratio of the company heavily. They are negatively correlated as with the increase of loss ratio, the financial health of the insurers gets worse leading to fall in the solvency ratio.

Wit and Kastelijn (1980) proposed 2-parameter beta distribution for modeling the incurred claims ratio and they fitted the model for 53 data points belonging to 10 insurance companies in Netherlands. They although mentioned the limitation of 2-parameter distribution which has a support level in the range $[0,1]$. The very fact that incurred claims ratio can exceed unity, which 2-parameter will always rule out. Accordingly, they also proposed a Weibull distribution which has support in [0, “). They estimated solvency margin based on the estimates of incurred claim ratio and expense ratio under different scenarios.

Ramlau (1982) commented the paper of Wit and Kastelijn (1980) and suggested some improvements in their model using the credibility methods. Campagne (1961) assumed all observed loss ratios to be stochastically independently and identically distributed with the same distribution, leading to the introduction of a greater variance into the data. He also commented that the inclusions and exclusions of companies from the dataset will play significant role as their loss experiences are expected to diverge significantly. Accordingly, he suggested for a comprehensive analysis of companies for solvency purposes according to lines of business, claim experience, reinsurance arrangements and other macro-economic factors. A similar study can be found in the Sandstrom (2006), which demonstrated for the Swedish data pertaining to the period 1996-2003.

Recently, Dreassi and Miani (2008) updated the parameters of the Campagne's model for the Italian non-life insurers for the dataset 2001-2006. They fitted the dataset through 2-parameter beta distribution using the method of moments. The study used a transformation in the data of incurred claims ratio in order to contain these with the support level of $[0,1]$.

In the present study, the authors propose 3parameter Burr distribution to model the solvency ratio. Burr distribution is a very versatile distribution and often used for insurance datasets, which happens to be highly (positively) skewed and leptokurtic in majority of the cases. Recently, Sastry and Sinha (2010) used the generalized 4-parameter Burr distribution for the famous Danish fire loss dataset and showed that it is quite competitive with the other mixture and complex distributions, as proposed by various researchers for the said dataset.

The probability density function of a 4-parameter Burr distribution is given by:

$$
\mathrm{f}(\mathrm{x})=\mathrm{a} \mathrm{k}\{(\mathrm{x}-\tilde{\mathrm{a}}) / \mathrm{a}\}^{\mathrm{a}-1} / \hat{\mathrm{a}}\left[1+\{(\mathrm{x}-\tilde{\mathrm{a}}) / \hat{\mathrm{a}}\}^{\mathrm{a}}\right]^{\mathrm{k}+1}
$$


The distribution function is defined as:

$$
\mathrm{F}(\mathrm{x})=1-1 /\left[1+\{(\mathrm{x}-\tilde{\mathrm{a}}) / \mathrm{a}\}^{a}\right]^{\mathrm{k}}
$$

Where, $\mathrm{k}(>0)$ and a $(>0)$ are the first and second shape parameters; $\hat{a}(>0)$ and $\tilde{\mathrm{a}}(0 \leq x<\infty)$ are scale and location parameters respectively.
The 3-parameter Burr distribution is the special case of the above 4-parameter Burr distribution, wherein $\tilde{\mathrm{a}}=0$. As mentioned above, we have used this distribution to our dataset, as plotted in Figure 5. We provide the descriptive statistics of this dataset in Table 5.

Table 5: Descriptive Statistics (Data points $=208$ )

\begin{tabular}{|l|r|l|r|}
\hline Mean & 2.1755 & Minimum & 1.02 \\
\hline Standard deviation & 0.7534 & Maximum & 4.68 \\
\hline 25\% Quartile & 1.660 & Range & 3.66 \\
\hline Median & 1.945 & Skewness & 1.4505 \\
\hline $75 \%$ Quartile & 2.370 & Kurtosis & 4.4619 \\
\hline
\end{tabular}

From the table, it can be observed that the underlying dataset of solvency ratio is positively skewed and leptokurtic. The three parameters of the

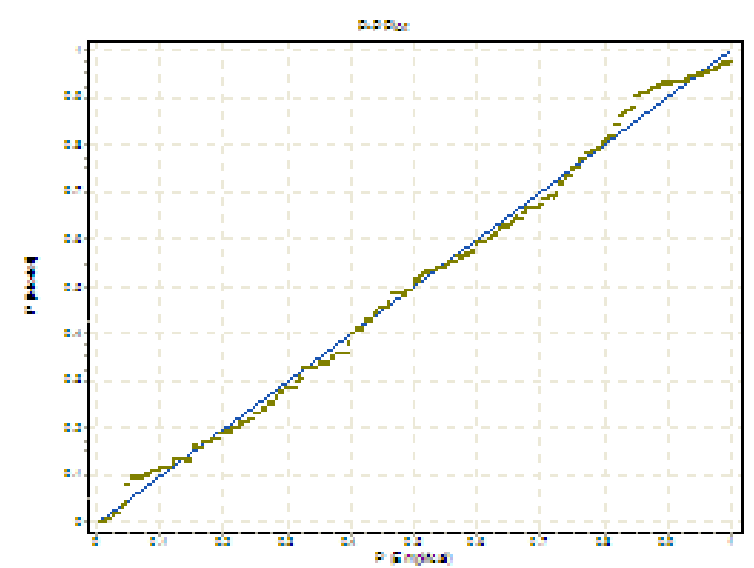

a.: distribution were estimated as $\mathrm{k}=0.23573, \mathrm{a}=14.406$, $\hat{a}=1.5792$. The $P P$ and $Q Q$ plots are exhibited in Figure 5.

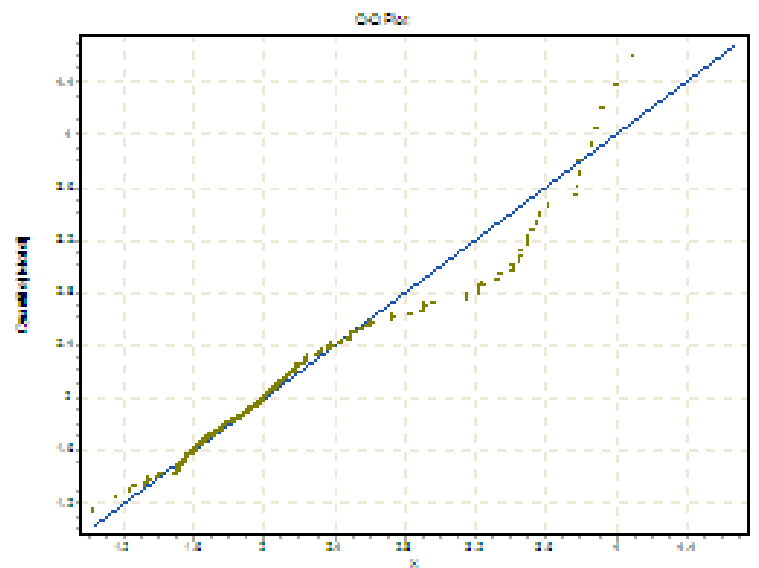

$-1+$

Figure 5: QQ-plot

Three test statistics, namely Kolmogorov-Smirnov (KS), Anderson-Darling (AD) and Chi-square revealed an appropriate fit for the underlying dataset and their computed values are $0.05799,0.77424$ and 8.2253 respectively. The appropriateness is also depicted in the PP and $Q Q$ plot. We provide our findings in Table 6. It can be seen that our proposed 3-parameter Burr distribution explains the underlying data well. The fitting curve is shown in Figure 6. 
Table 6: Observed and fitted quantiles of Burr model

\begin{tabular}{|c|c|c|}
\hline Quantile (\%) & Observed & Expected \\
\hline 5.00 & 1.51 & 1.43 \\
\hline 10.00 & 1.54 & 1.52 \\
\hline 25.00 & 1.67 & 1.68 \\
\hline 50.00 & 1.95 & 1.93 \\
\hline 75.00 & 2.37 & 2.37 \\
\hline 90.00 & 3.46 & 3.11 \\
\hline 95.00 & 3.79 & 3.82 \\
\hline 97.50 & 4.09 & 4.68 \\
\hline 99.00 & 4.60 & 6.13 \\
\hline
\end{tabular}

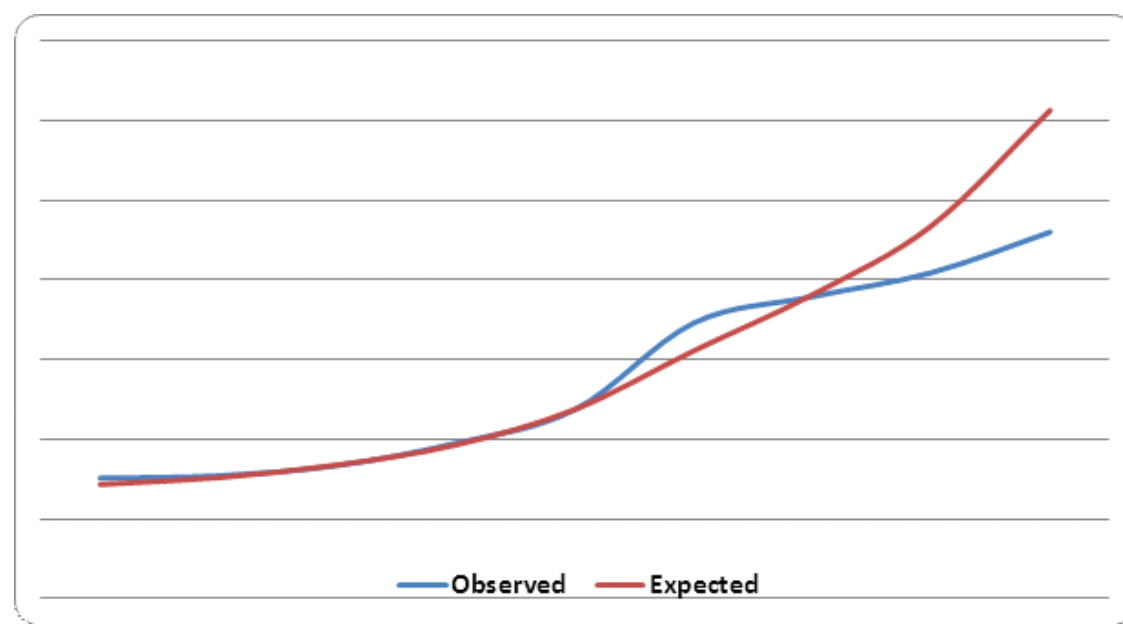

Figure 6: Plots of observed and fitted quantiles of Burr Model

\section{Discussion and Conclusion}

The Indian insurance industry is growing fast consequent upon privatization since year 2000 . The private insurance companies are in the process of gradual improvements on their solvency ratio, in terms of its variability, which are under reduction during the recent period of post-privatization. Assuming that the ratios are independently and identically distributed, fitting of the dataset is carried out through statistical distribution. It is observed that the 3-parameter Burr distribution explains the data of solvency ratio for the Indian non-life insurance companies quite well. Given this, it is observed greater number of defaults $(S R<1.50)$ from the model as compare to the actual observed data. The expected number is around 17 as against 10 actual defaults in the dataset of 208 observations. The median solvency ratio from the model is computed as 1.93 . The same is 1.95 for the observed dataset.

The model is based on the assumptions of IID, as indicated before. Accordingly, the interpretations of the results are based on the validity level of the assumption. Nevertheless, it provides a useful insight into the variations in the solvency ratios on a quarterly basis. 


\section{Further Studies}

1. We have modeled the solvency ratio using the dataset of the computed ratios, which are derived from two numbers viz. the Available Solvency Margin (ASM) and the Required Solvency Margin (RSM). It is suggested that rather than using the final ratio, it will be interesting to analyze these two numbers first, and their inter-relationship, as both are expected to be highly (positive) correlated. Modeling these two numbers and then estimating solvency ratios will be an interesting exercise.

2. Further, the input variables (viz. components of ASM and RSM) could be analyzed and attempted to estimate the solvency ratio through some multiple linear regression model. The input (independent) variables are the Assets and Liabilities of the Policyholders and the Shareholders accounts under the ASM segment, while the Gross Premium, Net Premium, Gross Incurred Claims and Net Incurred Claims are the endogenous variables under the RSM segment.

3. It would also be interesting to study the transitional movement for the solvency ratio under the Markov Chain set up and the stationary distribution could be derived, which would represent the scenario of random movement in the solvency ratio in one-step period (annual or quarterly) under the stage of complete stabilization of the Indian non-life insurance companies. This long-run stationary distribution would provide the estimates of various transition probabilities from one stage to another stage; for example, the probability of the solvency ratio of an insurer dipping below 1.50 level in the next year, given its solvency ratio is in the range of 2.00-2.50 this year.

\section{References}

Champagne, C (1961): Minimum standards of solvency for insurance firms, report to the OECD, $11^{\text {th }}$ March, 1961, TFD/PC/565.

Dreassi, A \& Miani, S (2008): The European solvency margin: an update for Italian non-life insurers, International Review of Business Research Papers, Vol. 4, No. 5, October-November 2008, 44-54.

Ramlau, H H (1982): An application of credibility theory to solvency margins: some comments on a paper by G W De Wit and W M Kastelijn, ASTIN Bulletin, Vol. 13, 37-45.

Sandstrom, A (2006): Solvency: models, assessment and regulation, Chapman \& hall / CRC, London.

Sastry, D V S \& Sinha, R K (2010): A revisit to Danish fire loss data, Conference Proceedings of the $13^{\text {th }}$ Global Conference of Actuaries (GCA) held in Mumbai in February 2010.

Wit, G W De \& Kastelijn, W M (1982): The solvency margin in non-life insurance companies ASTIN Bulletin, Vol. 11, 136-144.

\section{Authors' Profile}

R K Sinha and, M M Nizamuddin are the Deputy Director and Assistant Director in the Research \& Development (R\&D) Department of Insurance Regulatory \& Development Authority (IRDA), Hyderabad respectively. Their e-mail ids are rksinha@irda.gov.in and munshi@irda.gov.in.

Ameer Hassan is the Research Assistant in the Finance \& Accounts (F\&A) Department of Insurance Regulatory \& Development Authority (IRDA), Hyderabad. His e-mail ID is ameer.h@irda.gov.in

The views expressed in this paper are authors' personal views and do not necessarily represent the organizations they belong/belonged to. 